\title{
Surgical management of giant sphenoid wing meningiomas encasing major cerebral arteries
}

\author{
Pierre-Olivier Champagne, MD, Emile Lemoine, and Michel W. Bojanowski, MD, FRCSC \\ Department of Neurosurgery, University of Montreal Hospital Center (CHUM), Montreal, Quebec, Canada
}

\begin{abstract}
OBJECTIVE Sphenoid wing meningiomas are a heterogeneous group of tumors with variable surgical risks and prognosis. Those that have grown to a very large size, encasing the major cerebral arteries, are associated with a high risk of stroke. In reviewing the authors' series of giant sphenoid wing meningiomas, the goal was to evaluate how the extent of the tumor's invasion of surrounding structures affected the ability to safely remove the tumor and restore function.
\end{abstract}

METHODS The authors conducted a retrospective study of a series of giant sphenoid wing meningiomas operated on between 1996 and 2016. Inclusion criteria were meningiomas with a globoid component $\geq 6 \mathrm{~cm}$, encasing at least 1 major intradural cerebral artery. Extent of resection was measured according to Simpson grade.

RESULTS This series included 12 patients, with a mean age of 59 years. Visual symptoms were the most common clinical presentation. There was complete or partial encasement of all 3 major cerebral arteries except for 3 cases in which only the anterior cerebral artery was not involved. The lateral wall of the cavernous sinus was invaded in 8 cases $(67 \%)$ and the optic canal in $6(50 \%)$. Complete resection was achieved in 2 cases (Simpson grades 2 and 3 ). In the remaining 10 cases of partial resection (Simpson grade 4), radical removal (>90\%) was achieved in 7 cases $(70 \%)$. In the immediate postoperative period, there were no deaths. Four of 9 patients with visual deficits improved, while the 5 others remained unchanged. Two patients experienced transient neurological deficits. Other than an asymptomatic lacuna of the internal capsule, there were no ischemic lesions following surgery. Tumor recurrence occurred in 5 patients, between 24 and 168 months (mean 61 months) following surgery.

CONCLUSIONS Although these giant lesions encasing major cerebral arteries are particularly treacherous for surgery, this series demonstrates that it is possible to safely achieve radical removal and at times even gross-total resection. However, the risk of recurrence remains high and larger studies are needed to see if and how improvement can be achieved, whether in surgical technique or technological advances, and by determining the timing and modality of adjuvant radiation therapy.

https://thejns.org/doi/abs/10.3171/2018.1.FOCUS17718

KEYWORDS giant meningioma; vascular encasement; sphenoid wing; surgical management; cavernous sinus

$\mathrm{S}$ PHENOID wing meningiomas are a heterogeneous group of tumors that can arise anywhere along the sphenoid wing. They account for approximately $20 \%$ of supratentorial meningiomas. ${ }^{23,30}$ Cushing and Eisenhardt classified these lesions into middle, medial, and lateral according to the location of their origin along the wing. ${ }^{8}$ Consequently, the clinical presentation, risk of surgery, and prognosis can vary from case to case. ${ }^{30}$ Those that have grown to a very large size, encasing the major cerebral arteries, are particularly treacherous, and their surgical management is highly challenging with a high risk of stroke..$^{18,30}$ In reviewing our series of giant sphenoid meningiomas $(\geq$
$6 \mathrm{~cm}$ ) encasing the major cerebral arteries, our goal was to evaluate how the extent of the tumor's invasion of surrounding structures affected our ability to safely remove the tumor and restore function.

\section{Methods \\ Study Criteria}

This is a retrospective analysis of a series of giant sphenoid meningiomas operated on by the senior author (M.W.B.) between 1996 and 2016. Inclusion criteria were meningiomas with a globoid component $\geq 6 \mathrm{~cm}$ in their

ABBREVIATIONS ACA = anterior cerebral artery; $C S=$ cavernous sinus; $D S A=$ digital subtraction angiography; ICA = internal carotid artery; $M C A=$ middle cerebral artery; MPRAGE = magnetization-prepared rapid acquisition gradient echo; OC = optic canal; ON = optic nerve.

SUBMITTED November 30, 2017. ACCEPTED January 29, 2018.

INCLUDE WHEN CITING DOI: 10.3171/2018.1.FOCUS17718. 
widest diameter, arising along the sphenoid wing with encasement of at least 1 major cerebral artery: the supraclinoid internal carotid artery (ICA), the middle cerebral artery (MCA), and/or the anterior cerebral artery (ACA). We define encasement to be when at least a portion of the length of the artery is surrounded by the tumor, either partially, by at least $180^{\circ}(50 \%)$ of its circumference, or completely, as noted on preoperative MRI using magnetization-prepared rapid acquisition gradient-echo (MPRAGE) and/or thin-slice T2-weighted sequences. The extent of encasement was categorized into 3 approximations: $50 \%$, $75 \%$, and $100 \%$. We excluded meningiomas arising from the olfactory groove, petroclival meningiomas, and meningiomas arising from the cavernous sinus (CS).

\section{Data Collection}

Data were collected from the patient's medical file, the operative report, and the specimen's pathology report. Data collection focused on preoperative symptoms, imagery, surgical technique, immediate postoperative clinical neurological status, and time span before recurrence. Preand postoperative imaging was reviewed and correlated with intraoperative findings. We particularly looked for invasion of the CS or of the optic canal (OC), brain tissue edema, and encasement of the major cerebral arteries. Extent of resection was determined according to Simpson grade and postoperative images. Data were compiled in an electronic database and cross-checked for accuracy multiple times during collection. Our study was approved by our institution's ethics committee.

\section{Surgical Technique}

The goal of the surgical management of any giant sphenoidal meningioma is its complete resection, while obviously preserving surrounding neurovascular structures and their function. In cases in which complete resection poses a great risk of injury to neurovascular structures, the goal is the maximum safe removal of the tumor, which requires constant intraoperative surgical analysis and judgment. Because important structures are embedded within these giant tumors and since the brain is compressed by them, wide exposure is required. This minimizes brain retraction and allows early recognition of normal structures before proceeding with tumor resection. In our series, all patients were operated on via a pterional approach; an orbitozygomatic variant was not required. However, to push the temporal muscle away from the line of sight, interfascial muscular dissection was performed to expose the lateral orbit and the horizontal segment of the zygomatic bone, and to retract the temporal muscle posteroinferiorly. The sphenoid wing is drilled to reach at least the superior orbital fissure.

Upon opening the dura, to minimize brain retraction, dissection begins with a wide opening of the sylvian fissure. Dissection proceeds from the distal part of the fissure to its proximal part, because proximal normal arterial intradural blood vessels, hidden by the tumor, cannot be seen. The goal at this point is to identify branches of the MCA, just distal to the tumor. The tumor is resected little by little, alternately debulking and pursuing extracapsu- lar dissection to progressively expose the entire proximal MCA and its perforators, then the ICA bifurcation, and ultimately the entire intradural ICA and the optic nerves (ONs), while preserving the arachnoid plane whenever possible (Fig. 1). Sufficient debulking is essential, not only in creating the space in which to detach the tumor from the brain, blood vessels, and cranial nerves, but also in being able to proceed gently with minimal traction during the extracapsular dissection, particularly in cases when the tumor is fibrous or highly calcified. Minimal traction during dissection is essential to prevent injury to the surrounding structures, including the arteries and their perforators.

In our series, because of the size of these giant meningiomas, when judged necessary, exposure of the extradural ICA by removing the anterior clinoid process and the opening of the OC were performed late in the surgery, once the initially hidden intradural ICA and the ON had been identified. Either intradural or extradural approaches were used to resect the anterior clinoid process.

Brain retractors have not been used since 2005, except occasionally, and even then only for a short period of time once most of the tumor has been removed, to prevent the now very relaxed brain from filling the empty space thus created. In our series, despite some cases with a wellvascularized tumor, preoperative embolization was not necessary, nor was it necessary intraoperatively to initiate with devascularization of these large tumors at the base of the skull.

\section{Results \\ Patient Population}

From 1996 to 2016, a total of 680 various meningiomas, most of them skull base meningiomas, were surgically removed by the senior author (M.W.B.). Among them, 12 patients qualified for the selection criteria of this study. Of these 12 patients, 10 were women and 2 were men, with a mean overall age of 59 years (Table 1). Visual symptoms were the most common at presentation, affecting 9 patients (75\%). Of these 9 patients, 4 presented with visual field defect and the other 5 with visual acuity disturbance. Headache was a common symptom at presentation (6 patients, 50\%). Cognitive impairment with memory deficit was present in 6 patients (50\%). Motor symptoms in the form of contralateral hemiparesis were found in 4 patients (33\%). Extraocular movement disturbances were found in 2 patients (17\%), one with third cranial nerve palsy and the other with sixth cranial nerve palsy. One patient presented with mixed aphasia (Table 2).

\section{Tumor Characteristics}

All 12 patients underwent MRI, which included MPRAGE and/or thin-slice T2-weighted sequences, which in our experience offer images allowing for a better assessment of vessel encasement than MR angiography or CT angiography can provide. In our series, 3 patients underwent digital subtraction angiography (DSA) preoperatively, only 1 patient underwent MR angiography, and none of the 12 patients had a CT angiogram.

Mean tumor size at its widest diameter was $6.6 \mathrm{~cm}$ (range $6-8 \mathrm{~cm}$ ). The tumor was on the left side in 8 cases 
A Beginning of first session

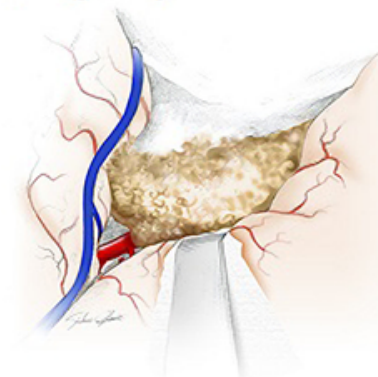

B End of first session

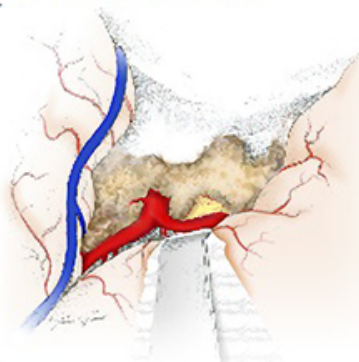

C Second session

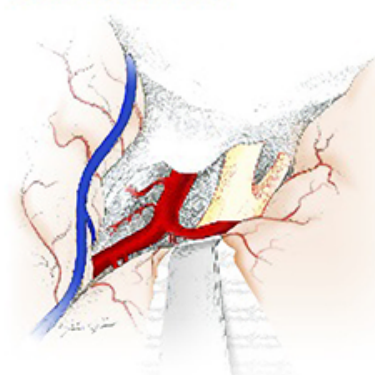

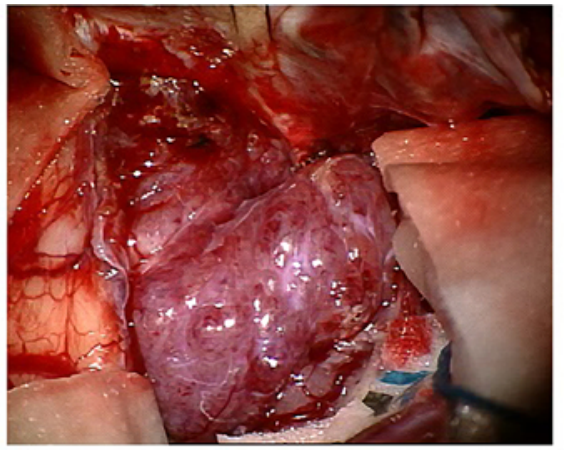
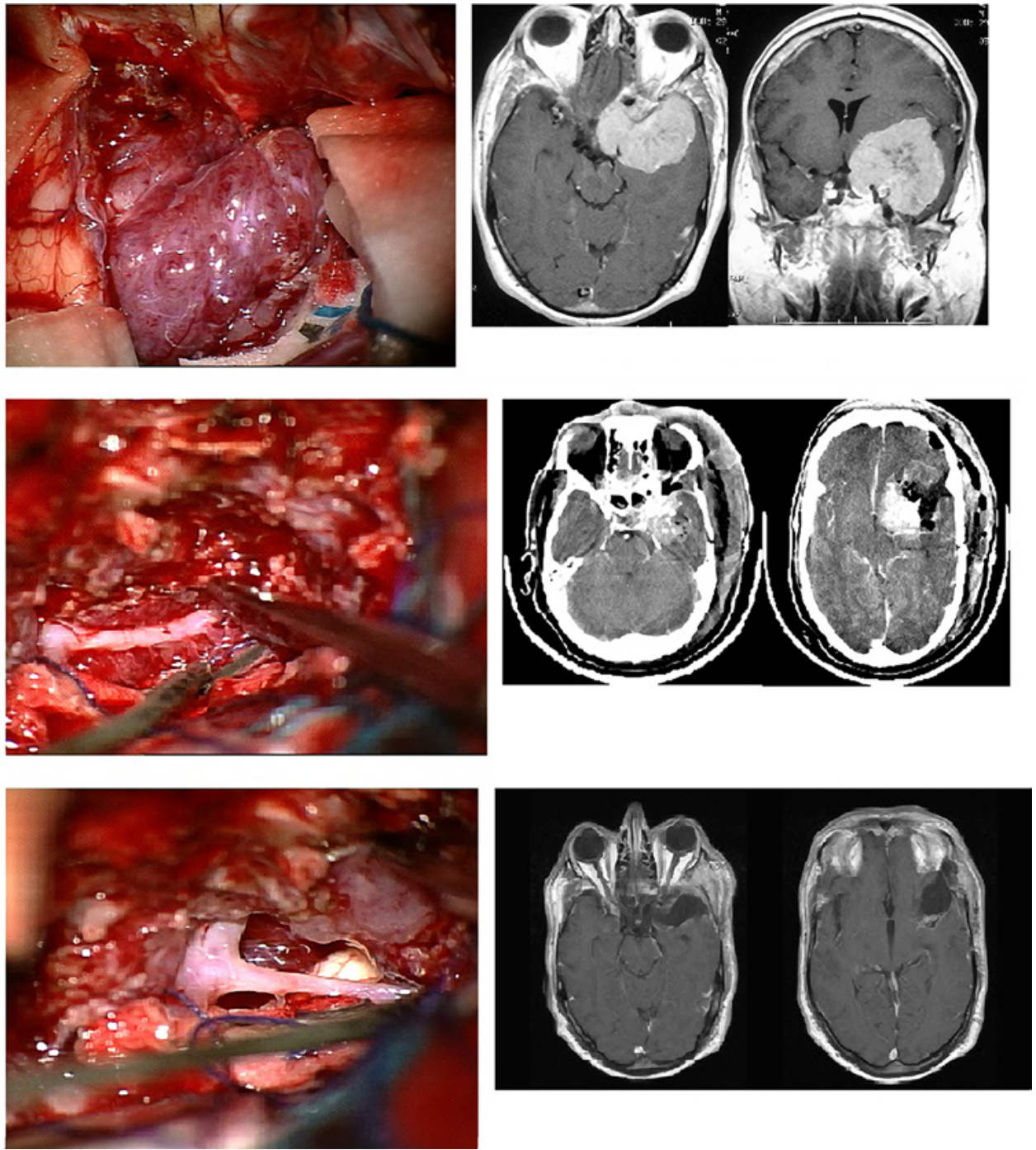

FIG. 1. Case 10. Resection of a giant sphenoid wing meningioma. A: Artist's rendering, intraoperative image, and preoperative T1-weighted MR image with Gd administration showing the tumor before resection. B: Artist's rendering, intraoperative image, and postoperative contrast-enhanced CT scan showing the remaining tumor at the end of the first surgical session. C: Artist's rendering, intraoperative image during the second session, and postoperative T1-weighted MR image with Gd administration showing gross-total resection. Copyright Michel W. Bojanowski (illustrations, left column). Published with permission.

$(67 \%)$ and on the right in 4 cases (33\%). Because of their huge size, and based on preoperative MRI and intraoperative findings, all except 1 of the meningiomas were assumed to originate from the middle segment of the sphenoid wing, just lateral to the anterior clinoid process; the exceptional case originated from the more external part. Complete encasement of the ICA was present in all cases. Complete encasement $(100 \%)$ of the MCA was present in 9 cases, $75 \%$ encasement in 1 case, and $50 \%$ encasement in 2 cases. Complete encasement of the ACA was present in 6 cases, $75 \%$ in 1 case, $50 \%$ in 2 cases, and the ACA was not encased at all by the tumor in 3 cases. No luminal narrowing was observed in our series. CS involvement was present in 8 cases $(67 \%)$ and the tumor extended into the OC in 6 cases $(50 \%)$. The ON was medially pushed by the meningioma most of the time ( 8 cases), and more rarely the tumor completely encased the $\mathrm{ON}$ (3 cases). In 1 case, the ON was pushed upward. Two tumors were high- ly calcified. Peritumoral edema assessed on preoperative MRI was severe in 4 cases, moderate in 2 cases, mild in 3 cases, and absent in 3 cases. Ten tumors were WHO grade I, and 2 were grade II (Tables 1 and 3).

\section{Surgical Treatment}

None of our cases underwent embolization prior to surgery. All tumors were approached via a pterional craniotomy; an orbitozygomatic variant was not necessary in this series. Three tumors were found to be very hemorrhagic during resection (Table 4). Tumor consistency was found to be fibrous in 5 cases and soft in 7. Complete macroscopic resection was achieved in 2 cases (1 Simpson grade 3 and 1 Simpson grade 2). The remaining 10 cases were left with residual tumor (Simpson grade 4): $90 \%$ or more of the tumor was resected in 7 of them (Figs. 2 and 3), $80 \%$ resected in 1 case, and $70 \%$ or less in 2 cases. Tumor rem- 
TABLE 1. Demographic data, tumor size, localization, and relationship with intracranial arteries and other structures

\begin{tabular}{|c|c|c|c|c|c|c|c|}
\hline \multirow[b]{2}{*}{ Case No. } & \multirow[b]{2}{*}{ Age (yrs), Sex } & \multirow[b]{2}{*}{ Tumor Size (cm) } & \multirow[b]{2}{*}{ Tumor Side } & \multicolumn{3}{|c|}{ Involved Vessel (\% encasement) } & \multirow[b]{2}{*}{ Other Involved Structures } \\
\hline & & & & $\mathrm{ICA}$ & MCA & ACA & \\
\hline 1 & $57, \mathrm{~F}$ & 6 & $\mathrm{Lt}$ & 100 & 100 & 100 & CS, OC \\
\hline 2 & $66, F$ & 6.5 & $\mathrm{Rt}$ & 100 & 100 & 100 & - \\
\hline 3 & $51, \mathrm{~F}$ & 7.4 & $\mathrm{Lt}$ & 100 & 100 & 75 & CS, OC, ON (encased) \\
\hline 4 & $66, \mathrm{~F}$ & 6.6 & $\mathrm{Rt}$ & 100 & 100 & 0 & CS, OC \\
\hline 5 & $69, \mathrm{~F}$ & 6 & $\mathrm{Lt}$ & 100 & 100 & 100 & CS \\
\hline 6 & $68, M$ & 8 & $\mathrm{Rt}$ & 100 & 75 & 50 & CS \\
\hline 7 & $61, F$ & 7 & $\mathrm{Lt}$ & 100 & 50 & 0 & - \\
\hline 8 & $79, \mathrm{~F}$ & 6 & $\mathrm{Rt}$ & 100 & 50 & 0 & - \\
\hline 9 & $68, F$ & 6 & $\mathrm{Lt}$ & 100 & 100 & 100 & CS, OC \\
\hline 10 & $45, M$ & 6.5 & $\mathrm{Lt}$ & 100 & 100 & 100 & CS, OC, ON (encased) \\
\hline 11 & $49, \mathrm{~F}$ & 6.5 & $\mathrm{Lt}$ & 100 & 100 & 100 & CS, OC, ON (encased) \\
\hline 12 & $26, F$ & 6 & $\mathrm{Lt}$ & 100 & 100 & 50 & - \\
\hline
\end{tabular}

nants were located on a main cerebral artery in 5 cases, in the CS in 3 cases, and along the lesser sphenoid wing in 1 case. In the 2 cases in which less than $70 \%$ of the tumor was resected, resection was limited by extensive calcification in 1 case and by the patient's inability to undergo subsequent surgery in the other, due to a preexisting clinical condition. Two cases necessitated 2 surgical sessions (Table 4).

\section{Postoperative Outcome}

In the immediate postoperative period, 2 patients had a new deficit: mixed aphasia in 1 case (case 5) and hemiparesis in the other (case 2; Table 2), with both deficits being transient and due to postoperative edema. Another patient (case 1) became hemiparetic due to significant brain edema requiring bone flap removal. This patient recovered in 10 days. Four patients remained neurologically unchanged from their preoperative state, while 5 others improved: 4 patients who had had visual symptoms and 1 patient who had had hemiparesis. The mean follow-up duration after surgery was 61 months (range 3-252 months). At the last follow-up evaluation, 6 patients were in a stable unchanged neurological state, 2 had progressive deficits, 3 were continuing to improve, and 1 died 2 years later due to progression of residual tumor in which less than $70 \%$ of the tumor had been removed (Table 2).

\section{Postoperative Imaging}

Clinically significant edema occurred in 3 patients, and all completely recovered. None of the cases had a hemorrhagic complication, as noted on the CT scan obtained routinely on postoperative day 1 . In 1 case, the CT scan revealed an ischemic lacuna in the posterior arm of the internal capsule, later confirmed on MRI. This lacunar infarct was fortunately asymptomatic. There was no other ischemic injury in our series (Table 4).

\section{Tumor Recurrence}

Five cases (42\%) experienced either a recurrence or progression of the residual tumor, with a mean time for re- currence of 61 months. The 7 others were stable at a mean follow-up of 30 months. The origin of recurrence was the site of the residual tumor in all but 1 case, in which recurrence occurred on the MCA following gross-total removal. Of those 5 tumors that progressed or recurred, 1 was treated with radiotherapy alone, 1 was treated with surgery alone, 2 were treated with both surgery and radiotherapy, and 1 was closely observed with no further treatment (Table 4).

\section{Discussion}

Giant sphenoid wing meningiomas $(\geq 6 \mathrm{~cm})$ encasing major cerebral arteries pose a great technical challenge in their surgical management. Because of their size and their mass effect, there is no question as to whether to proceed with surgery; the real challenge is during surgery. Their huge size engulfs surrounding vital structures, obscuring them from view. Moreover, at times the tumor adheres to these structures, making it very risky to remove it. $4,18,23$

Although such meningiomas may originate anywhere along the sphenoidal wing, in our series most of them originated from its intermediate segment just lateral to the anterior clinoid process, extending predominantly superiorly and laterally. Had they extended medially, visual symptoms would have prompted earlier diagnosis prior to the tumor having grown to such a large size. In our series, in 8 cases the tumor had invaded the lateral wall of the CS, and in 6 of these 8 cases the OC was also invaded. It is interesting to note that whenever the tumor had infiltrated the OC, the CS was also involved, but not inversely. This would also suggest that to reach such a large size before diagnosis, these tumors originating from the lateral side of the clinoid process first reached the CS, spreading then to the $\mathrm{OC}$ as they grew. Another reason why these meningiomas may reach such a huge size before diagnosis - other than the fact that they are slow growing-is that there is often no associated brain edema. In fact, in our series, despite the size of the lesions, 6 of 12 cases had no significant preoperative brain swelling. 
TABLE 2. Signs and symptoms associated with tumor at presentation, in the postoperative period, and on last follow-up

\begin{tabular}{ll}
\hline \multicolumn{1}{c}{ Deficit } & No. of Patients (\%) \\
\hline Preop & $9(75)$ \\
\hline Visual acuity defects & $4(33)$ \\
\hline Visual field defects & $5(42)$ \\
\hline Visual acuity disturbance & $6(50)$ \\
\hline Headaches & $6(50)$ \\
\hline Cognitive impairment & $4(33)$ \\
\hline Motor deficits & $2(17)$ \\
\hline Extraocular movement disturbance & $1(8)$ \\
\hline Aphasia & $1(8)$ \\
\hline Postop & $1(8)$ \\
\hline New mixed aphasia (transient) & $4(33)$ \\
\hline New hemiparesis (transient) & $5(42)$ \\
\hline Unchanged & $4(33)$ \\
\hline Improved & $1(8)$ \\
\hline Visual symptoms & \\
\hline Motor deficit & $6(50)$ \\
\hline Deficits on follow-up & $2(17)$ \\
\hline Stable & $3(33)$ \\
\hline Progressively worse & $1(8)$ \\
\hline Improved &
\end{tabular}

Not surprisingly, the main clinical manifestation was visual deficit. This visual deficit was not only related to the invasion of the $\mathrm{OC}$, but also due to the increased intracranial pressure caused by the size of the tumor and sometimes also due to brain edema. In addition, the mass effect and the elevated intracranial pressure produced cognitive dysfunction in half of our patients, symptoms seen more rarely in meningiomas from the middle segment of the sphenoid ridge, such as tuberculum sellae meningiomas. ${ }^{3,26}$ These symptoms may at times reach such a severe level that even following partial resection there is no improvement whatsoever, and consequently a second surgical session would be deemed ineffectual, as was the case in 2 of our patients (cases 2 and 3).

One worrisome aspect of the surgery in detaching the tumor from the main arteries is the extent to which they are encased. ${ }^{16,18,22,23,25,31}$ In all 12 of our cases, the ICA was completely encased. The MCA was also encased in all 12 cases, in 9 of them completely and in the 3 others partially. Only in 3 cases was the ACA not encased; thus, in 9 of 12 cases parts of all 3 main arteries were completely encased. It is interesting to note that whenever the ACA was encased, the MCA was always encased, if not completely, then partially. This information helps to anticipate technical difficulties in dissecting the tumor from these vessels and their perforators. However, as reported by other authors, and as noted in our series, no imaging criteria could predict which tumor is adherent enough to the major arteries precluding its safe complete resection. ${ }^{6,18}$ For the 3 patients who had had DSA, there was no correlation
TABLE 3. Tumor characteristics of the 12 patients with giant encasing sphenoid wing meningiomas

\begin{tabular}{|c|c|}
\hline Tumor Characteristic & Value (\%) \\
\hline Mean size $(\mathrm{cm})$ & 6.6 \\
\hline \multicolumn{2}{|l|}{ Side } \\
\hline $\mathrm{Lt}$ & $8(67)$ \\
\hline Rt & $4(33)$ \\
\hline \multicolumn{2}{|l|}{ Origin } \\
\hline Middle sphenoidal wing & $11(92)$ \\
\hline External sphenoidal wing & $1(8)$ \\
\hline \multicolumn{2}{|l|}{ Vascular encasement* } \\
\hline \multicolumn{2}{|l|}{ Supraclinoid ICA } \\
\hline $100 \%$ & $12(100)$ \\
\hline \multicolumn{2}{|l|}{ MCA } \\
\hline $100 \%$ & $9(75)$ \\
\hline $75 \%$ & $1(8)$ \\
\hline $50 \%$ & $2(17)$ \\
\hline \multicolumn{2}{|l|}{ ACA } \\
\hline $100 \%$ & $6(50)$ \\
\hline $75 \%$ & $1(8)$ \\
\hline $50 \%$ & $2(17)$ \\
\hline $0 \%$ & $3(25)$ \\
\hline \multicolumn{2}{|l|}{ Other involved structures } \\
\hline CS & $8(67)$ \\
\hline $\mathrm{OC}$ & $6(50)$ \\
\hline \multicolumn{2}{|l|}{ Edema } \\
\hline Severe & $4(33)$ \\
\hline Moderate & $2(17)$ \\
\hline Mild & $3(25)$ \\
\hline Absent & $3(25)$ \\
\hline \multicolumn{2}{|l|}{ WHO grade } \\
\hline I & $10(83)$ \\
\hline II & $2(17)$ \\
\hline
\end{tabular}

All data are given as number of patients (\%) except for size.

* Described in percentage as proportion of the circumference of the vessel being encased by the tumor.

between preoperative imaging of the degree of tumor vascularization or the degree to which major cerebral vessels were stretched and the level of difficulty encountered intraoperatively. As is the case for smaller lesions engulfing the arteries, it is only during surgery, following maximal debulking of the tumor, that one can assess if the tumor can be safely detached from the artery. In our series, no luminal narrowing was observed; when present, this characteristic may be potentially associated with a higher surgical risk.

Despite the extent of tumor encasement of the vessels and the invasion of the lateral wall of the CS, radical removal was possible in $9(75 \%)$ of the 12 cases, i.e., more than $90 \%$ of the tumor was removed; in 2 of these 9 cases, gross-total removal was achieved. Two cases required 2 surgical sessions, and in 1 gross-total removal was achieved. Table 4 lists the site of residual tumor in each 
TABLE 4. Surgical characteristics, extent of resection, and time before recurrence

\begin{tabular}{|c|c|c|c|c|c|c|}
\hline $\begin{array}{l}\text { Case } \\
\text { No. }\end{array}$ & Tumor Consistency & $\begin{array}{c}\text { Extent of } \\
\text { Resection (\%) }\end{array}$ & $\begin{array}{l}\text { Simpson } \\
\text { Grade }\end{array}$ & $\begin{array}{l}\text { Location of } \\
\text { Tumor Remnant }\end{array}$ & $\begin{array}{l}\text { Postop Ischemia or } \\
\text { Hemorrhage }\end{array}$ & $\begin{array}{c}\text { Time Before } \\
\text { Recurrence (mos) }\end{array}$ \\
\hline 1 & Fibrous & 95 & 4 & CS & Internal capsule lacuna & 24 \\
\hline 2 & Soft, hemorrhagic & 70 & 4 & Sphenoid wing & None & 24 \\
\hline 3 & Fibrous, calcified, hemorrhagic & $>50$ & 4 & Sphenoid wing & None & 36 (stable) \\
\hline 4 & Soft & $>90$ & 4 & MCA & None & 3 (stable) \\
\hline 5 & Soft, hemorrhagic & 80 & 4 & MCA & None & 48 (stable) \\
\hline 6 & Soft & $>90$ & 4 & MCA & None & 4 (stable) \\
\hline 7 & Fibrous & $>90$ & 4 & MCA & None & 3 (stable) \\
\hline 8 & Soft & $>95$ & 4 & Sphenoid wing & None & 60 (stable) \\
\hline 9 & Soft & $>90$ & 4 & MCA, CS & None & 42 \\
\hline 10 & Fibrous, very calcified & GTR & 2 & - & None & 60 (stable) \\
\hline 11 & Fibrous & $>95$ & 4 & CS & None & 48 \\
\hline 12 & Soft & GTR & 3 & - & None & 168 \\
\hline
\end{tabular}

GTR = gross-total resection

All patients underwent a pterional approach.

case. Of note, in $50 \%$ of the cases with a tumor remnant, the remnant was on a main artery: in our series, the main anatomical characteristic preventing gross-total removal of these giant meningiomas was the extent to which they adhered to the main cerebral blood vessels and their perforators. Yet, despite the extent of resection, there was no stroke in any of the 12 cases other than an asymptomatic lacuna involving the posterior limb of the internal capsule in 1 case, as revealed on postoperative MRI. This is likely because when a tumor is firmly attached to the vessels and difficult to remove, we do not hesitate to leave a remnant, although efforts are made to leave as little tumor as pos-
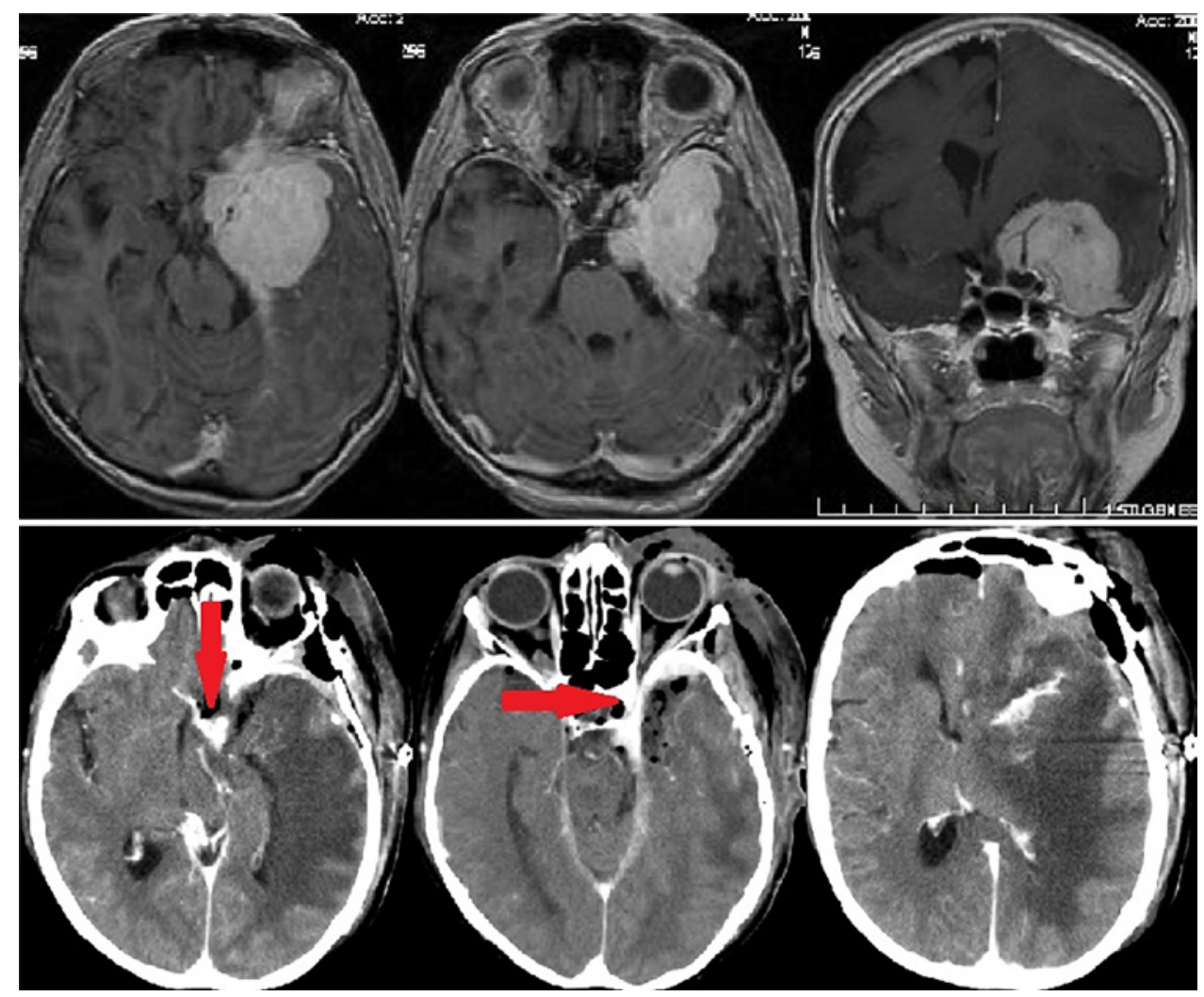

FIG. 2. Case 9. Upper row: Preoperative T1-weighted MR images with Gd showing a left sphenoid wing meningioma completely encasing the ICA, MCA, and ACA. Lower row: Postoperative contrast-enhanced CT scan showing residual tumor along the left CS and left proximal MCA (arrows). 

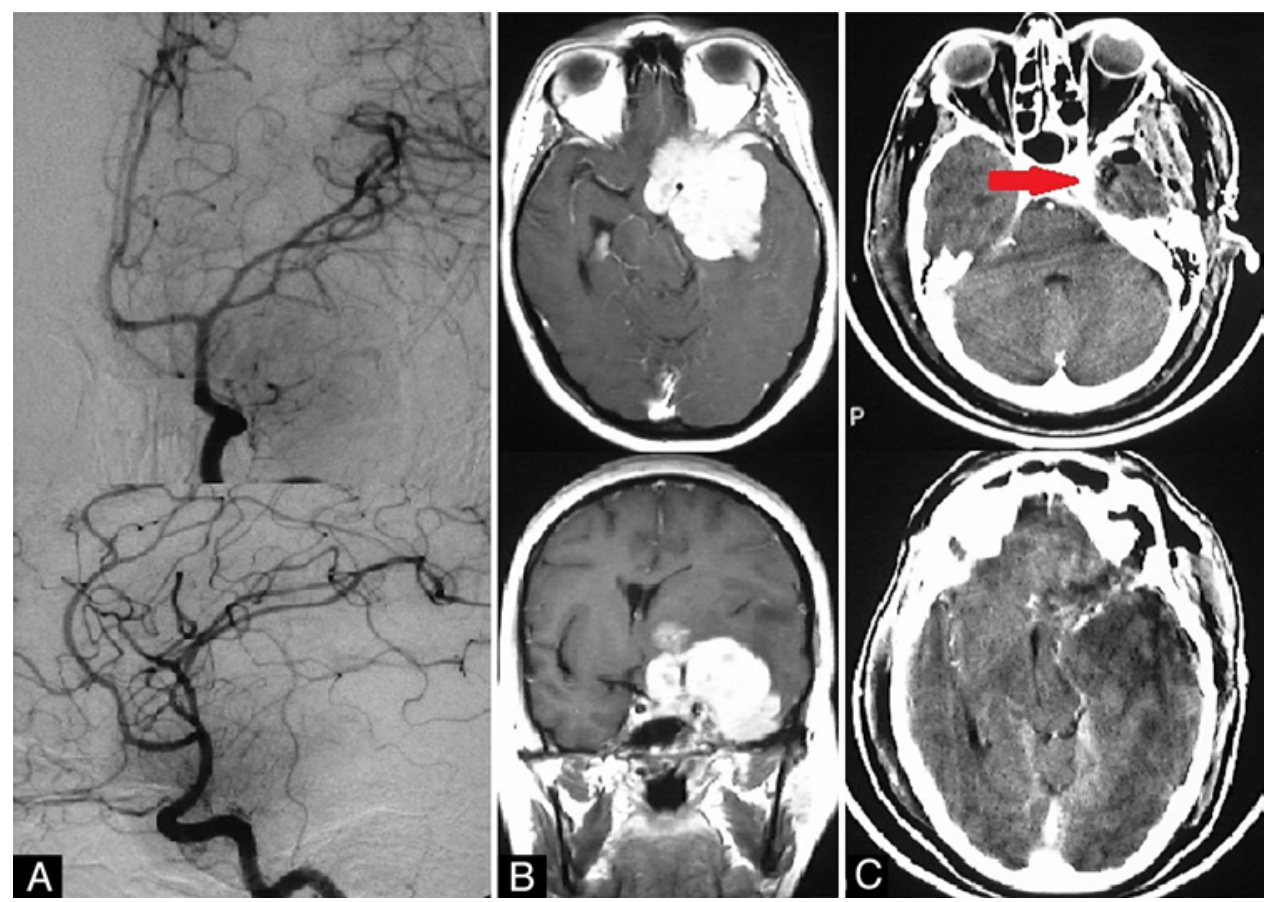

FIG. 3. Case 11. A: Preoperative angiogram of the left ICA showing a tumoral vascular blush and stretching of the left MCA. B: Preoperative T1-weighted MR image with Gd showing a meningioma of the left sphenoid wing completely encasing the ICA, MCA, and ACA. C: Postoperative contrast-enhanced CT scan showing residual tumor along the left CS (arrow).

sible. A significant rate of surgical complications has been reported with meningioma encasing major cerebral vessels. ${ }^{4,6,18}$ However, with a prudent approach using modern surgical techniques, the risk of arterial injuries is reported to be low. ${ }^{5,10,15,30}$
In our series, the second main anatomical characteristic preventing gross-total removal is CS invasion. Our tumoral resection was limited to outer-layer dura propria of the external wall of the lateral CS. Even today with modern microsurgical techniques, resection of meningio-
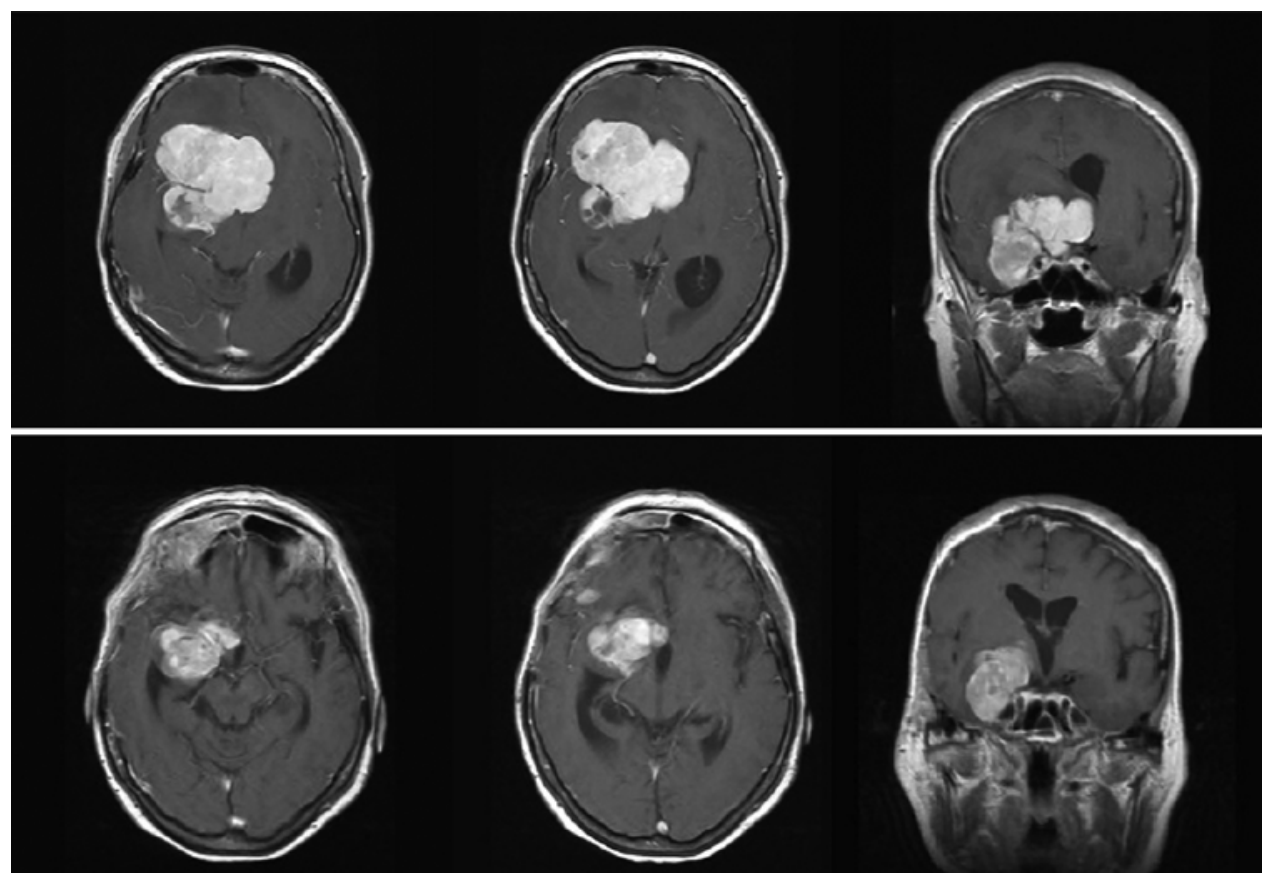

FIG. 4. Case 2. Upper row: Preoperative T1-weighted MR images with Gd showing a right-sided sphenoid wing meningioma completely encasing the ICA, MCA, and ACA. Lower row: Postoperative T1-weighted MR images with Gd showing partial removal of the tumor with significant residual tumor. 
mas involving the CS is associated with high morbidity regardless of the size of the entire tumor. ., $^{1,11,12,19,23,24}$ When resection is contemplated, it is most often limited to the lateral compartment of the CS, followed by observation, or radiation therapy for symptomatic patients in order to reduce the rate of morbidity. $1,14,17,19,23,27,28$

Although theoretically certain physical characteristics of the tumors, such as their hard or soft texture, the extent of their calcification, and/or the degree to which they are vascularized, would not prevent gross-total removal, they are nonetheless factors in determining whether more than 1 surgical session would be required. Obviously, highly calcified lesions (such as in case 10) or highly vascularized ones require more time for resection, and sometimes may not be completed in 1 session. The patient's clinical condition may determine whether he or she is suitable for multiples surgeries. In fact, this was so in 2 of our cases, resulting in only partial resection because a subsequent surgery was not recommended (cases 2 [Fig. 4] and 3).

During the immediate postoperative period, in all 12 cases there were no permanent neurological complications; 2 experienced a new neurological deficit in terms of mild transient aphasia and hemiparesis, which lasted less than 10 days. There was substantial improvement of vision within the first week in 4 patients, whereas in 4 other patients the neurological state remained unchanged. In addition, as previously noted, despite the encasement of the major cerebral arteries and the extent of resection, there was no stroke in any of the 12 cases other than an asymptomatic lacuna involving the posterior limb of the internal capsule in 1 case. Obviously, resection of these giant sphenoid wing meningiomas encasing major cerebral arteries allows adjuvant radiation therapy, which would be otherwise inappropriate in most, if not all, cases.

In our series, despite the fact that 9 of 12 cases underwent radical tumor removal, the rate of recurrence was significant. This is mainly due to the extent to which the tumor adhered to the arteries. These results do not support the hypothesis that leaving small amounts of tumor has little impact, or that many of the tumor remnants undergo growth arrest and remain dormant. ${ }^{29,30}$

Follow-up data of at least 2 years are available in only 9 of our 12 cases and revealed tumor recurrence in 5 of these 9 patients; in 4 of them, recurrence was at the site of the tumor remnant, and in 1 in whom gross-total removal had been achieved, recurrence was on the MCA. Because the degree of resection in most of our cases was Simpson grade 4 , one would expect the rate of recurrence to be high, emphasizing the need for long follow-up durations.

Radiation therapy is indicated after partial resection and in cases of tumor recurrence. , $^{7,13,20}$ However, recent studies assessing volume rather than diameter of residual tumor have demonstrated a significant recurrence in a short time span following radiation therapy. ${ }^{21}$ We must insist on the importance of aiming to remove as much of the tumor as possible when complete resection is not possible. Freeing the optic pathways should be a main goal. Determining how much or how little of the tumor to resect in cases when complete resection is not suitable is certainly one of the main challenges in the surgical management of these giant meningiomas, and requires surgical judgment and experience. Intraoperatively assessing the amount of tumor that has been removed is not always obvious, and it can be frustrating to note on postoperative MRI how much more of the tumor could have been removed. The use of intraoperative MRI or CT can certainly improve discerning how much more of the tumor can be safely removed.

\section{Conclusions}

Long-term prognosis for these giant sphenoid wing meningiomas is obviously related to the amount of resection. Although these giant lesions encasing major cerebral arteries are particularly treacherous for surgery, our series, albeit small, demonstrates that it is indeed possible to safely achieve radical removal and at times even gross-total resection. However, the risk of recurrence remains high and constant surveillance is required. Larger studies are needed to see if and how improvement can be achieved in surgical technique or technological advances, and by determining the timing and modality of adjuvant radiation therapy.

\section{Acknowledgments}

We would like to thank Ms. Lucyna Szpak for her editorial assistance.

\section{References}

1. Abdel-Aziz KM, Froelich SC, Dagnew E, Jean W, Breneman JC, Zuccarello M, et al: Large sphenoid wing meningiomas involving the cavernous sinus: conservative surgical strategies for better functional outcomes. Neurosurgery 54:13751384,2004

2. Aboukais R, Zairi F, Reyns N, Le Rhun E, Touzet G, Blond $S$, et al: Surgery followed by radiosurgery: a deliberate valuable strategy in the treatment of intracranial meningioma. Clin Neurol Neurosurg 124:123-126, 2014

3. Ajlan AM, Choudhri O, Hwang P, Harsh G: Meningiomas of the tuberculum and diaphragma sellae. J Neurol Surg B Skull Base 76:74-79, 2015

4. Al-Mefty O: Clinoidal meningiomas. J Neurosurg 73:840849, 1990

5. Behari S, Giri PJ, Shukla D, Jain VK, Banerji D: Surgical strategies for giant medial sphenoid wing meningiomas: a new scoring system for predicting extent of resection. Acta Neurochir (Wien) 150:865-877, 2008

6. Bonnal J, Thibaut A, Brotchi J, Born J: Invading meningiomas of the sphenoid ridge. J Neurosurg 53:587-599, 1980

7. Buglione M, De Bari B, Trevisan F, Ghirardelli P, Pedretti S, Triggiani L, et al: Role of external beam radiotherapy in the treatment of relapsing meningioma. Med Oncol 31:866, 2014

8. Cushing H: Meningiomas: Their Classification, Regional Behaviour, Life History, and Surgical End Results. New York: Hafner, 1962, Vol 1

9. Cusimano MD, Sekhar LN, Sen CN, Pomonis S, Wright DC, Biglan AW, et al: The results of surgery for benign tumors of the cavernous sinus. Neurosurgery 37:1-10, 1995

10. Day JD: Cranial base surgical techniques for large sphenocavernous meningiomas: technical note. Neurosurgery 46:754-760, 2000

11. De Jesús O, Sekhar LN, Parikh HK, Wright DC, Wagner DP: Long-term follow-up of patients with meningiomas involving the cavernous sinus: recurrence, progression, and quality of life. Neurosurgery 39:915-920, 1996

12. DeMonte F, Smith HK, al-Mefty O: Outcome of aggressive 
removal of cavernous sinus meningiomas. J Neurosurg 81:245-251, 1994

13. Elia AE, Shih HA, Loeffler JS: Stereotactic radiation treatment for benign meningiomas. Neurosurg Focus 23(4):E5, 2007

14. Forster MT, Daneshvar K, Senft C, Seifert V, Marquardt G: Sphenoorbital meningiomas: surgical management and outcome. Neurol Res 36:695-700, 2014

15. Honig S, Trantakis C, Frerich B, Sterker I, Kortmann RD, Meixensberger J: Meningiomas involving the sphenoid wing outcome after microsurgical treatment-a clinical review of 73 cases. Cent Eur Neurosurg 71:189-198, 2010

16. Ishikawa M, Nishi S, Aoki T, Takase T, Wada E, Oowaki H, et al: Predictability of internal carotid artery (ICA) dissectability in cases showing ICA involvement in parasellar meningioma. J Clin Neurosci 8 (Suppl 1):22-25, 2001

17. Ivan ME, Cheng JS, Kaur G, Sughrue ME, Clark A, Kane AJ, et al: Association of morbidity with extent of resection and cavernous sinus invasion in sphenoid wing meningiomas. J Neurol Surg B Skull Base 73:76-83, 2012

18. Kattner KA, Fukushima T: Management of vascular invasion during radical resection of medial sphenoid wing meningiomas. Skull Base 11:99-104, 2001

19. Klinger DR, Flores BC, Lewis JJ, Barnett SL: The treatment of cavernous sinus meningiomas: evolution of a modern approach. Neurosurg Focus 35(6):E8, 2013

20. Maclean J, Fersht N, Short S: Controversies in radiotherapy for meningioma. Clin Oncol (R Coll Radiol) 26:51-64, 2014

21. Mansouri A, Larjani S, Klironomos G, Laperriere N, Cusimano M, Gentili F, et al: Predictors of response to Gamma Knife radiosurgery for intracranial meningiomas. J Neurosurg 123:1294-1300, 2015

22. McCracken DJ, Higginbotham RA, Boulter JH, Liu Y, Wells JA, Halani SH, et al: Degree of vascular encasement in sphenoid wing meningiomas predicts postoperative ischemic complications. Neurosurgery 80:957-966, 2017

23. Nakamura M, Roser F, Jacobs C, Vorkapic P, Samii M: Medial sphenoid wing meningiomas: clinical outcome and recurrence rate. Neurosurgery 58:626-639, 2006

24. O'Sullivan MG, van Loveren HR, Tew JM Jr: The surgical resectability of meningiomas of the cavernous sinus. Neurosurgery 40:238-247, 1997

25. Ouyang T, Zhang N, Wang L, Li Z, Chen J: Sphenoid wing meningiomas: surgical strategies and evaluation of prognostic factors influencing clinical outcomes. Clin Neurol Neurosurg 134:85-90, 2015
26. Saha R, Jakhar K, Kumar R: Sphenoid wing meningioma presenting as cognitive impairment. Shanghai Jingshen Yixue 28:173-176, 2016

27. Sindou M, Nebbal M, Guclu B: Cavernous sinus meningiomas: imaging and surgical strategy. Adv Tech Stand Neurosurg 42:103-121, 2015

28. Solmaz I, Tehli O, Temiz C, Kural C, Hodaj I, Kutlay M, et al: Surgical strategies for the removal of sphenoorbital meningiomas. Turk Neurosurg 24:859-866, 2014

29. Sughrue ME, Kane AJ, Shangari G, Rutkowski MJ, McDermott MW, Berger MS, et al: The relevance of Simpson Grade I and II resection in modern neurosurgical treatment of World Health Organization Grade I meningiomas. J Neurosurg 113:1029-1035, 2010

30. Sughrue ME, Rutkowski MJ, Chen CJ, Shangari G, Kane AJ, Parsa AT, et al: Modern surgical outcomes following surgery for sphenoid wing meningiomas. J Neurosurg 119:86-93, 2013

31. Verma SK, Sinha S, Sawarkar DP, Singh PK, Gupta D, Agarwal D, et al: Medial sphenoid wing meningiomas: Experience with microsurgical resection over 5 years and a review of literature. Neurol India 64:465-475, 2016

\section{Disclosures}

The authors report no conflict of interest concerning the materials or methods used in this study or the findings specified in this paper.

\section{Author Contributions}

Conception and design: Bojanowski. Acquisition of data: all authors. Analysis and interpretation of data: Bojanowski, Champagne. Drafting the article: all authors. Critically revising the article: Bojanowski. Reviewed submitted version of manuscript: Bojanowski. Approved the final version of the manuscript on behalf of all authors: Bojanowski. Administrative/technical/material support: Bojanowski. Study supervision: Bojanowski.

\section{Correspondence}

Michel W. Bojanowski: Notre-Dame Hospital, Centre Hospitalier de l'Université de Montréal, QC, Canada. michel.bojanowski. chum@ssss.gouv.qc.ca. 